\title{
Conversation with Daniel Goleman about the relationship between the person viewing art and the art itself
}

\author{
PERLA GIANNI FALVO, Art Perception International, Italy \\ GIOVANNI VALERI MANERA, Art Perception International, Italy \\ JOEL ZOSS, Catalan Publishing, USA
}

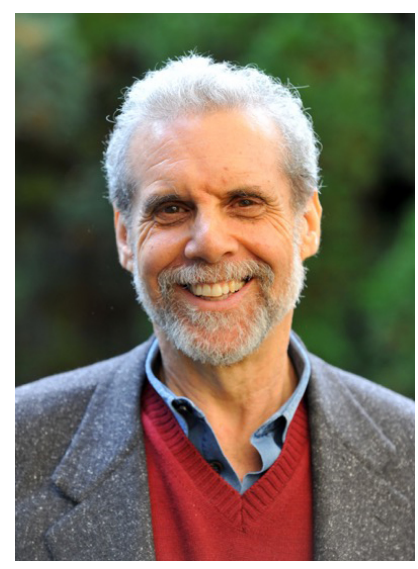

Daniel Goleman, best known for his worldwide bestseller "Emotional Intelligence," is most recently co-author of "Altered Traits: Science Reveals How Meditation Changes Your Mind, Brain and Body." A meditator since his college days, Goleman has spent two years in India, first as a Harvard Predoctoral Traveling Fellow and then again on a Post-Doctoral Fellowship. Dr. Goleman's first book, "The Meditative Mind: The Varieties of Meditative Experience," is written on the basis of that research, offering an overview of various meditation paths. Goleman has moderated several Mind and Life dialogues between the Dalai Lama and scientists, ranging from topics such as "Emotions and Health" to "Environment, Ethics and Interdependence." Goleman's 2014 book, "A Force for Good: The Dalai Lama's Vision for Our World," combines the Dalai Lama's key teachings, empirical evidence, and true accounts of people putting his lessons into practice, offering readers guidance for making the world a better place. Having worked with leaders, teachers, and groups around the globe, Daniel Goleman has transformed the way the world educates children, relates to family and friends, and conducts business.

Key words:

Art perception, Emotional Intelligence, Neurosciences, Meditation, Receptive Mindset.

SDH Reference:

Perla Gianni Falvo et al. 2018. Conversation with Daniel Goleman about the relationship between

the person viewing art and the art itself. SDH, 2, 1, VI-XI.

DOI: $10.14434 /$ sdh.v2i1.26872

\section{Perla Gianni Falvo: Buongiorno!}

Daniel Goleman: Buongiorno! Can I just start reflecting on the subject? Telling you my thoughts?

First of all, it makes more sense for me to frame this relationship between the person viewing art and the art itself in terms of mindfulness and brain function rather than emotional intelligence per se. Emotional intelligence in my view has four parts: there's self-awareness, there's self-management,

Authors' address: Perla Gianni Falvo and Giovanni Valeri Manera, Art Perception International, Via Orcagna 53, 50121, Florence, Italy; email: perla@artperception.org and giovanni@artperception.org; Joel Zoss, Catalan Publishing, 900 Division Street, Nashville, TN 37203, USA; email: joelzoss@joelzoss.com.

(C) [2018] by the authors; licensee Studies in Digital Heritage, IU, Bloomington (IN), USA. This article is an open access article distributed under the terms and conditions of the Creative Commons Attribution License (CC BY-NC). 
there's empathy, and there's relationship skills. There are some cross connections, but I think the more immediate links are between brain function, meditation, perception of art, and empathy. Let me explain.

In our book Altered Traits my co-author, Richard Davidson, a neuroscientist at the University of Wisconsin, and I go through about 6,000 peer-reviewed journal articles on meditation and pick the top 60 -just 1\%-of the very strongest studies and explain what they reveal about how mindfulness and meditation alters brain function. The two immediate impacts that I think are relevant to someone going to an art exhibit are, first, that it makes people more focused, better able to concentrate and ignore distractions, which you must do if you are going to stand in front of a painting and have a rapport with what that painting is telling you about the world. The other immediate impact is that meditation is very calming, and that means that the part of the brain that reacts to stress is quieter or recovers more quickly. I think that being calm and clear is the best mental state for a person who's going to an art exhibit. So, I think getting people into that mindful state may be one of the very best ways to prepare them to have real empathy for a painting, for a piece of art, a sculpture, to be really open to receiving whatever it is the art has to offer.

One interesting question is, how, as someone enters a museum or a gallery, can we change their mental state so that they're in this focused, calm, and receptive mindset? This means leaving behind the state of mind that people are ordinarily in while they are walking down the street, or in their offices, or in their homes. In other words, we tend to live in a universe of mental distraction, lack of focus, where we pay attention to whatever is most dominant or most pressing-or actually what's most emotionally upsetting. It turns out that people spend most of their free time with their minds wandering to problems they're having in relationships. This is data from a study at Harvard.

You want people to leave that mind behind as they enter the exhibit, and one thing you said-contact with art can be like a meditation-stimulates a thought from me, and that is to make the first experience at an exhibition a virtual reality event where you capture the person's senses. That's what virtual reality does, it creates a world that you want them to perceive. What if that initial experience is a kind of a meditation, maybe just a focus on the breath, maybe a voiceover where you tell people to just ignore whatever thoughts come up, let them go, just be with the natural flow of your breath. This is a very simple meditation that can be done very quickly, and if that's experience number one when people enter an exhibit, then I think you might help people get as close as they can to the optimal mind state for going through the rest of the exhibit, whatever it is. Those are my thoughts.

Joel Zoss: I'm envisioning an antechamber that's kind of a meditation room before one enters the exhibit proper.

DG: I like that. So, the first part of the exhibit is called the preparation room. I don't know if it's called that, but it is functionally that. And in that room my feeling is that people welcome a guide. The guide might be a voiceover that explains what inculcates the right mental state to get the most out of the experience you're about to have, and directs you to sit down in a quiet, semi-dark room. Maybe it's saying, focus on your breath, let go of other thoughts, and so forth. It does that for a few minutes and then says, okay, now enjoy the exhibit.

JZ: Right. And this could be like five minutes?

Studies in Digital Heritage, Vol. 2, No. 2, Publication date: December 2018 
DG: Exactly. I like that. I don't know, what do think about that?

PGF: I agree with this. In some of my workshops I've tried similar approaches. But those workshops were for just a few people. Maybe we can expand this sort of preparation to a larger number of people in a museum setting. Sometimes I think we could invite people to a museum just to see one work of art.

DG: That's interesting. So, there's an interaction effect. Two things occur to me. One is that, for example, in New York, if you go to The Museum of Modern Art, one of the first things that happens as you walk toward the exhibit itself is that there's a room where you can get headsets. The headset is actually a guided tour of the exhibit. In this room that we're imagining, maybe you get a headset just for the preparation experience. So, there might be one room where in the headset all you do is listen to the instructions, the guided, artistic meditation, or whatever you want to call it. Then you go to the rest of it. Anyway, that's just my thought.

Giovanni Valeri Manera: Maybe headsets could guide a larger number of people though an introduction into a focused state of mind. But the real issue for us is that while these sorts of approaches have been tried, as Perla said in small numbers, the point is also to remain focused, not only to start in the right space, but to stay there. And that is something else.

DG: That was my thought exactly. The brain alternates between what's called an orienting response and habituation. The orienting response is something that happens when you look at a piece of art, when you look at something new, original, fresh, and surprising, and the brain perks up. The brain activates, and so you actually perceive it sensually more fully and can get very absorbed in it. This is I think an ideal state to look at a piece of art. But then the brain habituates. Habituation means it closes down and you habituate to things that are routine, that you've seen hundreds of times. When you walk to work the same way every day you don't really see the things along the way as you did the first time you took that walk. That's because the brain is no longer interested, it's just categorizing: oh, that's a building, that's the park, that's whatever, and otherwise doesn't spend any energy registering it. But in an art exhibit you want people to stay in an orienting state all the time, and one way to do that is by having surprises along the way. I don't know what the surprise would be. Something that wakes up the brain.

JZ: A lot of Perla and Giovanni's work relies on constantly introducing new ways of looking at art. One of their projects involves what they call the Perception Room ("Chamera di Percezione" ${ }^{1}$ ), a room you can walk into where huge, life-size, bigger than life-size, projections of a piece of art surround you-floor, ceiling, four walls-

DG: Perfect. Works perfectly. That's the kind of thing I'm envisioning. Or imagining.

JZ: So the brain, once it awakens, you want to keep it awake.

\footnotetext{
1 "Chamera di Percezione" was an exhibition project developed by Perla Gianni Falvo for the first "Digital Heritage Congress" held in Marseille, France, in October 2013. It demonstrated an innovative augmented reality presentation of Raphael's painting "Madonna of the Goldfinch," using a room where the user could see large-format high-definition images of the painting projected on the walls, making it possible to penetrate the painting while also revealing the recent restoration process. More details are available on the exhibition catalog: Perla Gianni Falvo, Raffaello: Madonna of the goldfinch, in e-catalogue of the 2013 Digital Heritage International Congress Expo, S. Pescarin, A. Clay, L. De Luca eds., ISBN 978-88-902028-1-0.
} 
DG: Yes. Keep it awake. And the way you would do that is by every so often having a new experience like that, which is out of the ordinary.

JZ: This might be done be peeling away different layers of perception for a given work of art, for instance by showing what X-rays reveal beneath a painting. These are precisely the kinds of studies that Perla and Giovanni are pursuing.

DG: I think that's perfect. I think that's wonderful because that helps people see in a new way, which is very activating to the brain, engrossing. When people are interested the brain is more active. So, I think you're actually already on the right track, from my point of view.

GVM: You are very kind. I wanted to ask you your take on the seven-minute attention span. I don't remember who mentioned this, but the idea is that normally the human being after seven minutes loses attention and tends to wander off.

DG: I think that seven minutes is a little mythic, like "ten thousand hours." What it means is that after some time-and it varies enormously from person to person and situation to situation-after a certain amount of time, let's say seven minutes, you get habituated, is what it's saying.

GVM: We saw an interesting study about what people remember following a museum visit that said the vast majority of people who go to a museum completely forget what they've seen unless they went there to view a specific piece of art. So, people wander in, they see everything, they forget everything. One thing we are working on is, instead of showing them 10,000 things, maybe we show them one thing.

DG: In 10,000 ways-

GVM: Exactly. Maybe that is the rule. In 10,000 ways, but in an experience that is unforgettable.

DG: Exactly. But let me say something, Giovanni. In terms of the cognitive sciences, "forgetting" means you didn't pay attention in the first place. The more attention you pay the better you remember. So, I think what happens in an ordinary exhibit where you have a hundred pieces of art is that you habituate, which means you're walking through it, but you're distracted, thinking about what you're going to have for lunch or something. In other words, you're not actually seeing the art. So, by keeping attention high, you create experiences that are unforgettable.

There's something called "flashbulb memory." Everyone I know who was alive at the time remembers what they were doing when John F. Kennedy was assassinated. And that's because those kinds of events wake up the brain totally. And so, you capture in memory what was happening at that moment. What you're trying to do, it sounds like, is to create not quite that intense an experience, but rather a higher intensity experience of the moment that activates full attention, which means it will be remembered better. On the other hand, you still want to prepare people. Because you can look at the same thing a thousand ways and habituate too.

JZ: Well, two things pop into my mind. Traditionally, in Lakota [American Indian] culture, when you're going to have a council to decide important things you begin with an entertainer who tells jokes, often quite off-color. Only after everybody at the council is laughing do you start working on the serious issues. 
DG: That's great!

JZ: The thing that performers know, is that one reason to have an opening act at a concert is that it takes people a minimum of about twenty minutes after they come in and sit down to fully arrive and give you their attention. If you don't have an opening act, the first ten or twenty minutes of the show are often a bit of a throwaway, because the people aren't there yet. They're sitting in the seats, but they're still arriving.

DG: Right, can you speed up the arrival time, is my question? And you know, laughter oxygenates the brain, it's another way to activate the brain. So, there's some neuroscience behind that too. Which of course the Lakotas knew intuitively. So maybe something really funny is helpful with the arts too.

JZ: These are ways of getting people in the mood, as it were.

DG: Exactly. When you say "in the mood" it's also I would say in that optimal state, is the way to put it. The brain being activated and attentive.

PGF: When we talked before about how people focus on art, you said people needed continuing surprises or novelties to keep focused, and that this can be achieved by introducing new elements and points of view-directing the perception of the people like the director of a film, I want to say. You suggest it would be useful to make a special time to prepare people for viewing art, with an introductory meditation, for instance, and perhaps restricting the number of things they see while continuing to show different levels and details of a work of art using radiography, infrared, and other technologies that enable us to see things we normally cannot see with our eyes.

DG: So, the principle in brain science is that the brain becomes more active and alert when it confronts something new, novel, or surprising. Art itself is new and novel, and what's surprising is the way you're presenting it, I think.

GVM: So, if I understand you, just to be clear on this point, your idea or suggestion is to have a director sort of role in this work so that we can direct people to different levels of emotional involvement with the work of art. Our capacity will be to identify within the artwork different levels, to make it new and surprising using infrared vision or things that are not visible to the eye, in order to achieve this connection and keep it there. We have to keep people focused.

DG: So, a couple of things. One is that I liked that you said "emotional involvement" because emotion and attention are different aspects of the same thing. Emotion directs attention, and then attention can stimulate emotion. When I say "attention" you can almost insert "emotion." By getting people to pay more attention you're making the experience more emotionally impactful. The other thing is, I don't think you want to overwhelm, I think it's more a matter of pacing. For example, if you have a completely white-covered, white-painted room and one piece of art in it, the eye is going to be riveted to that piece of art, but it's because nothing else is distracting you. So, I think another element that you can use to your advantage is not just guiding the person, but pacing, and by pacing I mean that things could be very straightforward and then all of a sudden something surprising happens. You're very focused on one thing and suddenly-whatever the surprise is, the X-ray or something-pops up. So, it's some combination, like a melody almost. 
GVM: So exactly, if I understand you well, more than being overwhelmed, it's the pattern, it's the rhythm, it's the succession, that matters.

DG: And the surprise is part of the pattern. But it's an unexpected part of the pattern.

PGF: I agree, I totally agree. I think that in art perception, we need to direct the experience of art perception like a film, so people have the experience, and we need to work on those aspects.

DG: Right, I like your metaphor of the art curator as the director, like for a film. And that's exactly right because when you direct a film, you're designing an experience. When you create an exhibit, you're also designing an experience.

PGF, JZ, GVM: Thank you very much for your time.

Received September 2018. 